\title{
Study on the Crisis and Countermeasure of Rural Red Cultural Relics Protection in Northwest China
}

\author{
Xin Wang \\ Lanzhou Jiaotong University College of Art Design, Lanzhou, 730070
}

Keywords: Northwest Region; Rural Red Cultural Heritage; Beautiful Village

\begin{abstract}
Under the background of urbanization, how to protect the rural cultural ecology and develops the unity of the rural economy as a hot topic in the study of rural planning and construction, more and more attention by domestic and foreign scholars. In view of the problems in the protection of rural red cultural sites in northwest China, this paper combines the general theory of the protection and development of rural red cultural resources and the construction of "beautiful countryside" to explore the rationality and protection of the protection and utilization of the red cultural sites in the countryside Regional cultural landscape formation, improve the old revolutionary base areas of the villagers income for the construction of rural landscape in the northwest to provide constructive suggestions.
\end{abstract}

\section{Introduction}

With the national "beautiful rural" construction policy continues to advance, set off a new upsurge in rural construction, and now "beautiful village" has become a synonym for the construction of new socialist countryside in China. The spatial pattern of the village is optimized, the infrastructure and living conditions are improving, and the village appearance has made great changes, and the result is more remarkable. But the survey found that in the process of construction of some very unique rural landscape is dying, mainly in two aspects: on the one hand, the trend of rural hollow is increasing, a large number of elite loss, farmland barren, traditional houses collapsed, traditional culture On the other hand, the new rural construction projects and modern chemical and agricultural production is in full swing, there are trends in the trend of real estate, due to the lack of overall planning led to the rural environment is quietly suffering from destruction (1); on the other hand, the new rural construction projects and modern chemical and agricultural production is in full swing, The In particular, the rural areas in the northwest region, as the focus of the distribution of China's red cultural heritage area, the birthplace of China's earliest red revolutionary regime, the end of the Long March victory of the Chinese workers and peasants in the Red Army, a large number of time-span Large, influential, regional characteristics of the rich, rich variety of red cultural resources; in the geographical distribution of space, showing a large scattered, small, cross-regional, ethnic minority areas together to create the characteristics [2]. Due to the serious lack of planning system and the lack of attention of managers, the level of "beautiful countryside" construction is low, combined with unreasonable development model for a long time, has brought serious challenges to the protection of rural red cultural heritage The Sustainable Development of New Socialist Countryside.

\section{Definition of Rural Red Cultural Sites}

Some scholars believe that the red cultural heritage is since 1840, by the advanced Chinese people try to save China, the transformation of China's activities can be created to reflect the development of modern Chinese history, historical and cultural value of the remains, these relics include cultural relics Buildings, major events, folk oral traditions, song opera performances, social practice traditions, anniversaries and festivals, scientific theories on the transformation and development of Chinese society, advanced values and the use of The impact of handicrafts and 
other content [2]. Some scholars believe that the red cultural heritage in a broad and narrow sense, broad sense refers to the historical trend, promote the spirit of patriotism in all revolutionary activities in the condensation of human landscape and spirit; and narrow sense refers to the establishment of the Communist Party of China after the leadership of the broad masses of people The second domestic revolutionary war, the War of Resistance Against Japan, the historical traces and spiritual treasures formed during the war of liberation [3].

In order to facilitate the study, the red cultural heritage mentioned in the article, especially the Chinese Communist Party leading the people in the revolution and the war to create great achievements in the formation of a number of special revolutionary cultural resources [4].

Rural red cultural heritage refers to the red cultural heritage remains a considerable part of the rural settlement, subordinate to the scope of the red cultural heritage. According to its attributes and values, the performance of "physical", "knowledge" and "spirit" three levels: in kind for the revolutionary cultural relics, revolutionary ruins and buildings; knowledge for the red heritage of the various memories, recorded historical and cultural knowledge; Spirit refers to the spirit of the red culture of the heritage, it reflects the revolutionary ideals, moral and values, such as Jinggangshan spirit, Yan'an spirit, the spirit of the Long March [5].

Rural red cultural sites, generally refers to the red revolutionary commemorate the villages and towns, revolutionary war sites, revolutionary commemorative buildings [6]. In fact, China's rural red cultural landscape sites varied and rich in content, but also includes martyrs cemetery, travel, road and bridge, arsenal, ordnance repair, clothing factory, pharmaceutical factory, meeting, training and other sites [4]. They are the material form of cultural heritage, with historical representation and non-renewable.

\section{Village Red Cultural Heritage Protection Facing the Crisis}

The process of urbanization in rural areas is profoundly affecting the face of China's rural areas. At present, the northwest rural red cultural sites protection and development of the main problems:

First, due to the lack of urban planning, the lack of overall scientific planning guidance, resulting in rural red cultural sites have been varying degrees of damage, damage, or its surrounding environment has been damaged and caused by the phenomenon of uncoordinated. It mainly reflected in three aspects: First, the regional characteristics of too formal sense. Some local governments with rural housing projects, resettlement projects such as retro planning, image project, too much emphasis on visual beauty, commonly used in a certain period of style style on behalf of the style of regional architecture, big change, one-sided pursuit The form of the environment, ornamental and cultural visualization symbolizes the traditional houses of precious and diverse villages in the countryside, one of the original natural villages being razed to the ground and a large number of new reinforced concrete buildings Rational "dress", the village in the gorgeous appearance is presented under the uniform, style of a single style. Second, the design approach to the concept of urbanization. Some villages in the construction of infrastructure, due to the lack of necessary planning supervision and leadership of personal aesthetic preferences, showing blindly follow the fashion, copy the domestic and foreign cities or other developed areas of the construction model, with the perspective of urban planning rural planning, Regardless of the natural conditions of the village, the villagers living habits and daily behavior needs, the design of the pursuit of change, change the ocean, full of small Western, large square, wide road, artificial river, pruning plants and other international landscape elements And the style, resulting in the lack of new artificial landscape and the surrounding environment echo, spatial scale disorders, the details of the design is also the lack of human care, the original single function of the rural activities of the space is too small divided into a number of functional areas, regardless of the actual needs of rural night Lighting effect [7]. Third, the protection and development of rural red cultural sites lack the goal to lead, not to protect the development of revolutionary sites and the development of local economy to consider, lack of long-term constructive planning and extensive in-depth propaganda mobilization, development and utilization lag.

Second, the rural red cultural sites in the northwest are mostly distributed in remote areas with 
poor traffic, low economic and cultural development, lack of awareness of their values, lack of protection, and difficulties in census and protection. At present, especially the idea of economic construction as the center, the people's belief in the crisis, the revolutionary history, revolutionary people and their spirit began to weak, the protection of historical and cultural heritage of the sense of mission and sense of responsibility increasingly fade. In addition, the local managers of the protection of rural red cultural relics is not enough attention, a serious shortage of investment, "do not collapse, not down, not bad" to become the first choice of cultural relics management policy, resulting in some rural red revolutionary sites become scattered Abandoned, need to repair to restore the original appearance. Even in some remote areas, free to destroy, in the site to build a new house, repair works, basically lost as revolutionary relics should have the educational function and commemorative significance [3].

Third, the lack of effective management and protection of rural red cultural sites, there is no special protection of institutions and departments, the lack of appropriate authority. Resulting in these scattered in the village of the site protection, repair work has always been in the independent support of individual departments of the situation, the lack of cooperation with other departments, the community did not respond, which is caused by a large number of revolutionary sites the most serious cause of the root causes.

\section{Strategies for the Protection of Rural Red Cultural Relics in Northwest China}

At present, the state more and more attention to the unique historical and cultural values and protection of the rural landscape, especially in the May 27, 2015 the country issued the "beautiful rural construction guide" (GB32000-2015), for the country "beautiful rural" construction provides a framework Sexual and directional technical guidance standards. It is of great significance to protect the red cultural sites in the countryside.

Adhere to the "protection and development both, scientific management" of the ideological approach. In the method, the protection of rural red cultural sites into urbanization, try to establish a red cultural heritage protection and development of the overall theoretical framework to achieve the red cultural protection and development of interdisciplinary development, to guide the "beautiful rural" landscape planning and construction practice The In the content, based on the development of regional red cultural resources, from the perspective of the development of ecological culture, efforts to solve the "beautiful countryside" under the background of the construction of rural red cultural relics protection and development of the problem; the same time, the combination of red culture and spiritual civilization, To create a regional characteristics of the rural cultural landscape, so that the red culture to be inherited.

To protect the red cultural sites is a starting point, attention to the protection of the overall environment of the village to ensure that the diversity of rural landscape and characteristics of the northwest. First, there is a need to develop a range of conservation plans for the original rural village form and to determine the type and level of representative red cultural sites within the region. Secondly, by analyzing the comprehensive value of the development of rural red cultural relics, it clarifies the functional orientation and planning and construction goal of rural development. In the optimization of the rural spatial pattern, it is required to maintain and develop the characteristics of the original landscape, to minimize the new building scale, form and color of the traditional village body erosion and destruction; especially in the rural red cultural relics surrounding environment development and Construction should take the principle of prudence, not only to pay attention to the construction of the living environment within the country and improve the living standards, but also attach importance to the overall ecological environment of the village and cultural value, so that the construction of rural landscape activities to not destroy the ecological environment as a prerequisite, Transformation should also be appropriate, should try to maintain the original style, take the road of sustainable development.

Scientific and orderly planning is a prerequisite for the development of rural landscape. Under the current socio-economic conditions, how to adhere to the protection and development of rural red cultural sites in the northwest balance, highlight the regional cultural theme is difficult to study. 
Therefore, in the planning and design of the protection of rural red cultural sites, the concept of sustainable development is used to carry out the principles of symbiosis and development of people and landscape. Various ecological activities can not violate the ecological characteristics of the landscape. For the development of red rural tourism, we must coordinate with the production and living of the local villagers to ensure the development of tourism projects (such as red rural tour, red scenic tour, red cultural experience activities) and the construction of local facilities and culture. In the environment to create, pay attention to the local cultural characteristics and the spirit of space to create the local functions, make full use of local local elements, namely native plants, stone, living utensils, folk customs, according to the rural regional cultural characteristics, the red cultural connotation into Specific environmental design, emphasizing the participation of the public, to build a harmonious and natural, with regional characteristics of the landscape, so that the villagers built a new sense of identity and sense of belonging; at the same time in the protection of cultural landscape and regional culture, The development of appropriate, distinctive industries, the establishment of scientific and progressive way of life, so that the rural red cultural landscape has a distinctive feature and lasting appeal [8].

The sustainable development of the rural landscape must be based on the healthy development of the rural economy. Based on the rural red cultural sites, the integration of rural tourism, improve the economic income of farmers to solve the employment of rural personnel to maintain rural social stability, promote the development of local economy and expand the rural landscape protection and utilization of the way [9]. This paper analyzes the existing advantages and challenges of the protection and development and utilization of the red cultural heritage resources in different regions by defining the protection values of the existing red cultural landscapes in the rural areas of the Northwest region, and further developing the problems and challenges of the current protection and development and utilization Red rural tourism, to enhance the attractiveness of rural red landscape, and promote the transformation of rural economic structure. Of course, in the process of developing red rural tourism, it is necessary to correctly handle the relationship between the protection and development of red cultural landscape sites [8], but also to strengthen the publicity and education of rural residents, to raise their awareness of conscious protection and it recognizes the intrinsic value of the rural red cultural landscape.

Through the development of red rural tourism, it not only highlights the particularity of the rural landscape, but also excavated the economic value of the rural red cultural landscape; both to solve the new rural construction in the development of production, the development of rural economy and landscape protection between the contradictions, The rural residents consciously into the rural red cultural landscape protection and planning and construction to the initiative, so that the village to re-vitality and vitality, to achieve the coordinated development of rural landscape protection and utilization. Is to thoroughly implement and implement the general secretary of Xi Jinping proposed "to use the red resources, the red tradition to carry forward, the red into the good transfer."

\section{Conclusion}

Northwest region as the focus of China's red culture distribution areas mostly belong to the economically underdeveloped areas. The protection and use of rural red cultural sites as an important part of the construction of "beautiful countryside" can be an important means to promote the development of the rural environment, society and economy as a whole. Which can not only help all sectors of society to fully understand the red cultural landscape resources in the northwest region, but also to explore the development of rural red cultural sites in the northwest of the train of thought to promote the sustainable development of rural red culture; not only to protect the characteristics of the Northwest rural style, Landscape layout, improve the rural human environment effect, to achieve the rural red cultural heritage protection and urbanization construction coordinated development, but also play a red cultural resources of patriotism education, promote social core values, promote spiritual civilization construction and so on is of great significance. 


\section{References}

[1] Lin Qing. The value of rural landscape and sustainable development path [J]. Landscape Architecture, 2016 (8): 27-37

[2] Chen Li Chang. Five provinces in the northwest red cultural heritage protection and tourism development research [D]. Kaifeng: Henan University .2014: 5-6, 19-20

[3] Su Lijuan. Gansu red tourism resources development research [D]. Lanzhou: Lanzhou University .2006: 5-6,26-27

[4] Liu Jianping, Li Shuangqing. The basic connotation, present situation and reason analysis of rural red cultural heritage [J]. Development Research, 2008 (4): 121-124

[5] Liu Jianping, Li Shuangqing. On the protection of rural culture and the protection of rural red cultural heritage [J]. Journal of Xiangtan University, 2009, 33 (6): 89-93

[6] Wang Hao. "Journal of Chongqing University of Science and Technology, 2016 (12): 88-91 (in Chinese with English abstract)

[7] Wang Xin. (3): 57-59 (in Chinese with English abstract) "Journal of Architectural Education in Institutions of Higher Learning"

[8] Zhang Lvshui, Liu Chunqing, Chen Feiping. Construction of Rural Landscape under the Construction of Socialist New Countryside and Its Protection Countermeasures [J]. Fujian Forestry Science and Technology, 2009, 36 (1): 263-266

[9] Jiang Zaofa. Rural landscape protection under the background of urbanization [J] .Jiangxi Social Sciences, 2013 (2): 241-244 